\title{
THE PAST AND PRESENT OF TRANSFUSION MEDICINE
}

\author{
*Sitalakshmi.S, *Anuradha Srikrishna, *Shanthala \\ Devi $A$ M, and *Prema Damodar
}

Blood transfusion has developed as a practical clinical technique. Its development has progressed from ignorance to science and from cruelty to civilization over hundreds of years. Transfusion has made great contribution for saving lives and expanding operation coverage. Blood letting was widely practiced for a variety of medical conditions from the time of Hippocrates and yet transfusion only became a common place therapeutic intervention less than 100 years ago. Although the association of blood with life and vitality was recognized by primitive man, the transfusion of blood was not possible until Harvey described circulation in 1628. The transfusion of blood was only one of the many scientific competitions in which the citizens of France and England engaged in 1600s. This laid the foundation for transfusion therapy that were built in 100 years later. The development of transfusion medicine started from the attempts to transfuse blood in animals in the $17^{\text {th }}$ century and the first fruits were seen in the $2^{\text {nd }}$ half of $19^{\text {th }}$ century ${ }^{1}$

The English were the first to transfuse blood from one animal to another and the French from animal to man. James Blundell was the first person credited with transfusing blood from one human to another in 1818 when he successfully treated postpartum haemorrhage by direct transfusion of human blood and this represented the beginning of the modern era of transfusion medicine. Initially blood transfusion was carried out with considerable success even without any knowledge of blood

* Department of Clinical Pathology, St. John's Medical College and Hospital, Bangalore - 34 
groups. Differences in compatibility was recognized even before differences within a species. This was followed by the discovery of ABO blood group system by Karl Landsteiner and the Rh blood group system in the year 1940 together with Levine and Wiener ${ }^{2}$.

The rapid and inevitable coagulation of blood imposed a natural limit to the quantity of fresh blood that could be transfused in the early days. Blood transfusion was then performed by a surgical technique involving temporary anastomosis of the artery of a donor with that of the vein of a recepient. However the problem associated with this surgical approach included the need for a donor to be available at the time of surgery and it was not easy to assess how much blood has passed from the donor to the recepient, resulting in hypotension in the donor or circulatory overload of the recepient. Use of defibrinated blood by collecting it in an open container and stirring to promote clotting was another approach of blood transfusion. The need for a stable, non toxic anticoagulant which could be added to the collected blood and permit long term storage was evident.

Richard Lewinsohn is credited with introducing sodium citrate into clinical practice as an anticoagulant. Acid-citrate-dextrose solution was then adopted for anticoagulation of donated blood to improve red cell survival on storage without any disturbance of acid base balance in the recepient. Citrate-phosphate-dextrose was subsequently adopted an anticoagulant to store blood up to 28 days ${ }^{3}$.

The first blood donor service in the world was established in London by Percy Oliver, Secretary of the Cambenwell Division of the British Rgd Cross in 1921. He was a civil servant who worked with refugees during the First World War, for which he was awarded the Order of the British Empire in 1918. He established a panel of potential donors who could be contacted at short notice to give fresh blood. His centre was called the British Red Cross Blood Transfusion Service.

Bernard Fantus, of the Cook County Hospital in Chicago, is credited with establishing the first Blood Bank in 1937 from which blood could be withdrawn provided it was previously deposited. Blood was collected through steel needles and rubber tubing into rubber stoppered bottles and stored in refrigerators for up to 10 days. The material was reused after washing and resterilisation. On occasion "vacuum bottles". were used to speed up the collection. The high incidence of pyrogenic reaction soon led to the development of disposable plastic blood collection equipment. It was Gibson who demonstrated that plastic systems were more flexible and allowed plasma removal after centrifugation ${ }^{4}$.

The Second world war provided a great stimulus for the development of blood transfusion services and development of Blood Fractionation. The value of plasma 
was appreciated as an alternative for plasma expansion. The first cell separator was developed by Edwin Cohn in 1951 which paved the way for component therapy. The availability of a refrigerated centrifuge facilitated blood component separation. The concept of transfusing whole blood to remedy a deficiency of any constituent, for example, plate. The development of fractionated blood products has had a dramatic impact on the lives of patients with Haemophilia. The subsequent development of lyophilized plasma derived concentrates was a further advance. But the risk of viral contamination with this product has a significant impact on the mortality and morbidity of patients with haemophilia. Recently recombinant factor VIII and IX concentrates have been available since 1994 and 1998 respectively.

The evolution of transfusion therapy for diseases requiring specific protein replacements (e.g.,hemophilia A and B) was dramatic over the second half of the $20^{\text {th }}$ century. Unfortunately, it was accompanied by extreme manifestations of transfusion-transmitted diseases, such as human immunodeficiency virus (HIV), hepatitis $B$, and hepatitis $C$. Technologic advances have resulted in even more "pure" replacement therapies for such diseases. Transfusion transmitted disease (TTD) is a major challenge to the transfusion services all over the world. The problem of TTD is directly proportionate to the prevalence of the infection in the blood donor community. In India, hepatitis B and C, HN, malaria, syphiliș, cytomegalo virus, parvo-virus B-19 and bacterial infections are important causes of concern. From donor screening to the development of viral attenuation techniques, every facet of production for these products was impacted by the exigent push for viral safety created by HIV and hepatitis. Almost invariably, this negatively affected the total product yield. At the beginning of the $21^{\text {st }}$ century, success in making plasma products safe from recognized and potential pathogens has dramatically increased societal pressures to produce a zero-risk, plasma-derived protein therapy. The advent of AIDS has raised a concern regarding transfusion transmitted diseases. Blood transfusion is safer than ever before through continued improvements in safe donor recruitment, screening of donors, testing of donated blood and appropriate clinical use of blood. The risk of residual infections is further reduced through inactivation of pathogens in blood components. On the horizon is pathogen inactivation of RBCs and Platelet products that potentially eliminates all viral and bacterial contamination. The high degree of success in preventing viral transmission is a scientific triumph ${ }^{4}$.

A well functioning blood service is dependent on people who are willing to come forward and give blood as a gift to those in need. This prerequisite brings a deeply human aspect to the blood service. A systematic work towards a blood supply which is safe, adequate and reliable is an important responsibility of a blood transfusion service. Total dependence of repeat voluntary donors and use of 
sensitive laboratory tests may help Indian blood transfusion services to reduce incidences of TTDs. Although emerging infections remain a future potential threat, increased aggressiveness of therapies and aging of population has resulted in increase in blood use as we enter the new millennium.

St. John's Medical College Hospital has a full-fledged Blood Bank which functions 24 hours. Blood is collected from replacement and voluntary blood donors. About 10,000 donors donate blood every year. The Blood Bank is well equipped with facilities for Blood component preparation and storage. The various Blood components prepared for transfusion are Packed red cells, Fresh frozen plasma, cryoprecipitate and platelet concentrate. $80 \%$ of the Blood collection is utilized for blood component preparation in order to make effective use of limited supply of safe blood. It is mandatory to test the blood for HIV, Hepatitis B \& C, Venereal diseases and malaria before transfusion.

\section{References}

1. Ernest Beutler, S.P Masoureds Preservation and clinical use of erythrocytes and whole blood in Haematology $4^{\text {th }}$ edition William J William Ernest Beutler, Allan J, Erbler, Marshall A Lichtman 199

2. The History of Blood Transfusion British Journal of Haematology 2000, 110.758-767

3. Katz L, Klein HG, Lipton KS, Gevitz C, Schmidt P.J Blood and disaster New England Journal of Medicine 2002, 347: $68-69$

4. Ernio C Rossi, Toby L Simon Transfusion in the new millennium in Rossi's principles of Transfusion Medicine $3^{\text {rd }}$ Edition Ed Toby L Simon; Walter H Dzik, Edward L Snyder, Christopher P Stowell, Ronald G Strauss, Lippincoft Williams and Wilkins 2002 